\title{
Does Neonatal Brain Ischemia Induce Schizophrenia-Like Behavior in Young Adult Rats?
}

\author{
H. TEJKALOVÁ ${ }^{1}$, M. KAISER ${ }^{1,2}$, J. KLASCHKA ${ }^{3}$, F. ŠŤASTNÝ ${ }^{1,4}$ \\ ${ }^{1}$ Laboratory of Biochemistry and Brain Pathophysiology, Prague Psychiatric Center Affiliated with \\ Charles University, Third Faculty of Medicine, ${ }^{2}$ Department of Neurosurgery, Neurocenter, \\ Liberec, ${ }^{3}$ Institute of Computer Science and ${ }^{4}$ Institute of Physiology, Academy of Sciences, Prague, \\ Czech Republic
}

Received June 29, 2006

Accepted October 3, 2006

On-line available November 6, 2006

\begin{abstract}
Summary
Perinatal cerebral hypoxia represents a major cause of obstetric complications and the resulting transient oxygen deficiency might belong to early risk factors for schizophrenia. The aim of this study was to evaluate possible long-term behavioral changes induced by one hour of continuous bilateral common carotid artery occlusion in 12-day-old male rats. Post-ischemic behavioral disturbances were evaluated in social (play) behavior on postnatal day 22 (PND 22), open field test (PND 35 and 50) and prepulse inhibition of the acoustic startle reflex (PND 50). Transient ischemia in neonatal rats was not significantly altered in social dyadic interactions evaluated in pre-weaning pups, but resulted in enhanced locomotor activity in pubertal rats (PND 35) and impaired prepulse inhibition of the startle reflex in postpubertal males (PND 50). These behavioral alterations suggest that perinatal hypoxic/ischemic insults may represent a risk factor for later manifestation of specific features relevant to schizophrenia in predisposed individuals.
\end{abstract}

\section{Key words}

Neonatal ischemia $\bullet$ Schizophrenia $\bullet$ Rat $\bullet$ Prepulse inhibition

\section{Introduction}

Several epidemiological studies have confirmed that fetal and perinatal insults associated with brain hypoxia can increase the risk of schizophrenia (Jones et al. 1998, Cannon et al. 2000, 2002) and have given credence to the neurodevelopmental hypothesis of schizophrenia (Weinberger 1987, Murray and Lewis 1987, Harrison 1999, Marenco and Weinberger 2000). Patients with schizophrenia had in their histories a particular excess of obstetric complications, such as premature rupture of fetal membranes, low birth weight, newborn immaturity, forceps delivery and resuscitation at birth (Verdoux and Murray 1998, review Cannon et al. 2004). These complications are frequently accompanied by hypoxic-ischemic brain damage during delivery (Rantakallio et al. 1987, Cannon et al. 2000, 2002, Zornberg et al. 2000, Dalman et al. 2001). Therefore, we can see that obstetric complications involving perinatal lack of oxygen, including intrauterine hypoxia and birth asphyxia (Trojan and Št'astný 1988, Jones et al. 2004) represent a significant risk. These and other findings suggest that perinatal hypoxia acts additively or interactively with genetic factors by influencing 
susceptibility to schizophrenia (Cannon et al. 2000, Zornberg et al. 2000). Because of methodological problems, however, a direct causative link between schizophrenia and hypoxia remains without definite conclusions (Cannon et al. 2004). It was suggested that animal modeling can be a useful tool for determining if brain hypoxic-ischemic episodes in animals can actually cause changes in behavior resembling those seen in schizophrenia (Boksa 2004). Earlier studies have already shown that alterations in neuronal pathways caused by obstetric complications can be reproduced in rats subjected to perinatal hypoxia (Antier et al. 1998, Balduini et al. 2000, Sandager-Nielsen et al, 2004). Suitable models of perinatal hypoxia, based on the bilateral ligation of the common carotid arteries (BCCA), have been established in immature rats (Jílek et al. 1968, Št’astný et al. 1971, Uehara et al. 1999). Under these conditions the neonatal brain does not suffer from anoxia (ischemia), but from oligemic hypoperfusion (stagnant hypoxia) (Choy et al. 2006).

Neurodevelopmental processes in neonatal rats continue during the first three weeks of postnatal life and reach the level of those observed in human newborns at the end of the second postnatal week (Romijn et al. 1991, Bayer et al. 1993). Therefore, rat pups at postnatal day 12 (PND 12) were used and subjected to one hour of continuous occlusion of both common carotid arteries. Changes in blood $\mathrm{pH}$ and blood gases were determined at the end of the hypoxic episode. Previous findings have revealed that stagnant hypoxia alters brain levels of glutamate/aspartate in 12-day-old rat pups (Jílek et al. 1968). Similarly, neonatal intracranial infusion of glutamate receptor agonists, quinolinic acid and $N$-acetylaspartyl-glutamate, to rat pups mimics animal models of schizophrenia, but with some behavioral differences (Št’astný et al. 2004, 2005, Bubeníková-Valešová et al. 2006). To determine whether the behavioral changes in the post-ischemic animals were already present early in life or emerged during life, rats were tested before puberty and after puberty using a battery of tests for screening of schizophrenia-like symptoms (social and exploratory behavior, sensorimotor gating).

The aim of this study was to evaluate - both during development and in early adulthood - changes in social (play) behavior (PND 22), reactivity in the open field paradigm (PND 35 and 50) and sensorimotor gating as revealed by the acoustic startle response and prepulse inhibition (PND 50). We investigated the effects of neonatal ischemia (PND 12) on behavior exhibiting strong links to changes seen in schizophrenia and discuss the validity of our "ischemic animal model" relative to this mental disorder.

\section{Methods}

\section{Animals and housing}

Albino male rats (Wistar/Han rats, breeding colony BioTest Ltd, Konárovice, Czech Republic) were used in all experiments. Litters were obtained one week prior to the start of the surgical procedures and rearranged so that each group contained eight males and two females. Cages with individual nests were kept in an environmentally controlled room under $12 \mathrm{~h}$ of light and $12 \mathrm{~h}$ of dark. On PND 28 the rat pups were weaned (the day of birth was designated as PND 0) and separated according to gender and experimental group into clear plastic cages. All procedures were conducted in accordance with the European Community Council Directives (86/609/EEC) and followed the guidelines of the National Committee for the Care and Use of Laboratory Animals. All behavioral experiments were performed in a soundproof room adjacent to the housing room between 8:00 $\mathrm{h}$ and 13:00 $\mathrm{h}$. Additionally, the animals were used only once in a randomized order for each type of behavioral test.

\section{Animal surgeries}

Twelve-day-old rat pups (males weighing 20-28 g) were anesthetized with halothane (3.0 \% for induction and $1.0-1.5 \%$ for maintenance) in a mixture of oxygen and carbon dioxide (95:5). The rat pups were placed in the supine position on a heating pad to maintain their rectal temperature constant $\left(36.5 \pm 0.5{ }^{\circ} \mathrm{C}\right)$. The common carotid arteries were exposed through a cervical incision along the ventral midline. With the use of a stereomicroscope, both nerve-vascular bundles were separated and the common carotid arteries were isolated and occluded (BCCAO) with ligatures (10-0 silk); the skin incisions were then temporarily closed. The surgeries were routinely completed in less than $10 \mathrm{~min}$.

After $60 \mathrm{~min}$ the ventral incision was reopened and the ligatures on the common carotid arteries were removed. The ventral incision was resutured and after one hour of recovery, the pups were returned to their mothers. The exception to this procedure involved rat pups used for arterial blood sampling. The sham-operated animals underwent the same surgical protocol (bilateral common carotid artery isolation) as the experimental rat pups; 
however, there was no ligation and subsequent occlusion of the common carotids.

\section{Blood gas analysis}

For blood gas analysis, 20 rat pups were chosen (10 from the experimental group and 10 from the shamoperated group). Sixty minutes after the initial procedure the animals were separated, re-anesthetized and blood samples were withdrawn from a drop of blood that formed after transection of the left carotid artery. Blood samples $(100 \mu \mathrm{l})$ were drawn into heparinized glass capillary tubes. Blood gas parameters (arterial $\mathrm{pH}$, arterial partial pressures of $\mathrm{CO}_{2}$ and $\mathrm{O}_{2}$ ) were measured using a $\mathrm{pH} /$ Blood Gas Analyzer, type-1620 (Instrumentation Laboratory, France).

\section{Social (play) behavior}

Social (play) behavior (frequency, duration and latency of pinning and social behavior unrelated to social play behavior) was assessed in paired animals on PND 22 to demonstrate the deficits of social functioning comparable to pre-schizophrenic symptoms. Male pups were tested as described by Vanderschuren et al. (1995). On the day of the experiment, the animals were isolated in plastic cages $(40 \times 23 \times 23 \mathrm{~cm})$, for $3.5 \mathrm{~h}$ prior to experimentation. The session consisted of placing two pups from different litters into the novel test arena for $15 \mathrm{~min}$. Each tested pair of animals came from the same group, i.e. both from the experimental group or both from the sham-operated group. The difference in body weight between the paired pups was less than $10 \mathrm{~g}$. The behavior of the paired animals was recorded on videotape and was evaluated using the program ACTIVITIES (Donát 1991). Playing behavior (pinning: one of the animals lying on its back and the other pup standing over it) and social behavior unrelated to social play behavior (following the approach of the tested partner, mounting-crawling over the test partner, sniffing-grooming any part of the body of the test partner, including the anogenital area) were noted. In addition to this, we also noted "solitude" behavior in which the pairs kept a distance of at least $10 \mathrm{~cm}$ from each other.

\section{Spontaneous activity in an open field}

Locomotor activity in the open field test was evaluated on PND 35 (pubertal) and PND 50 (young adult) rats. A clear plastic rectangular arena $(65 \times 45 \times 35$ $\mathrm{cm}$ high) was placed in a sound attenuated, white-light observation room. The floor of the arena was divided into
$4 \mathrm{~cm} \times 3 \mathrm{~cm}$ squares without any covering material. All tests started with the individual animals being initially placed in the center of the arena. During one 5-min session, the frequency, duration and latency of behavioral characteristics (rearing, crossing, immobility, floor sniffing, air sniffing, grooming) were tape-recorded and chronicled (Benešová et al. 2001) using the program ACTIVITIES. This PC program produces impulses (in $0.1 \mathrm{~s}$ intervals) that allow to calculate the number of occurrences, total duration (i.e. total time spent performing activity) and latency (i.e. time from beginning of observation to the first occurrence) of selected behavioral elements (recorded by key codes).

\section{Acoustic startle response (ASR) and prepulse inhibition} (PPI)

On PND 50 the rats were transferred to a room adjacent to the Acoustic Startle One-Chamber System (SR-LAB, San Diego Instruments, CA). Each tested rat was placed into a clear Plexiglas tube which was mounted on a Plexiglass frame with a piezzoelectric accelerometer. The entire apparatus was placed in a sound-attenuated and illuminated cabinet. The acoustic stimuli were provided by a loudspeaker mounted $24 \mathrm{~cm}$ above the test cylinder. A piezzoelectric accelerometer, mounted below the Plexiglass frame, detected and transduced movements within the cylinder. The delivery of the acoustic stimulus was controlled by the SR-LAB system software. The stimulus was digitized, rectified and recorded as 250 1-ms readings from stabilimeters. The magnitude of startle amplitude was defined as the average of readings.

Initially, the rats were pre-exposed to the startle pulse alone (12 times at P120 dB, inter-trial interval of $15 \mathrm{~s}$ ) and $5 \mathrm{~min}$ of habituation (70 dB [A] background white noise) two days before the experimental trials. At the start of the experiment, the choice of prepulses and their timing was made according to the design described by Ellenbroek and Cools (2002). The rats were exposed to 50 pseudo-randomly arranged trials (10 startle, 10 no stimulus and 30 prepulse inhibition trials), background noise was continuously generated throughout each session. The inter-trial period ranged from 10 to $20 \mathrm{~s}$ and the whole session lasted $17 \mathrm{~min}$. Different types of trials were presented pseudo-randomly throughout the session to exclude identical consecutive trials. Startle stimulus alone (PA) was $120 \mathrm{~dB}$ [A] of white noise, $30 \mathrm{~ms}$ in duration; whereas with the three different prepulses white noise with an intensity of either 73 (PP3), 75 (PP5) or 80 (PP10) dB [A] was delivered for $30 \mathrm{~ms}$ and then 
Table 1. Blood gas parameters of sham-operated (control) and BCCAO (ischemic) 12-day-old rat pups one hour after bilateral common carotid artery occlusion.

\begin{tabular}{|c|c|c|c|c|c|}
\hline Group & $\mathbf{p H}$ & arterial $p \mathrm{CO}_{2}(\mathrm{kPa})$ & arterial $p \mathrm{O}_{2}(\mathrm{kPa})$ & sa $\mathrm{O}_{2}($ in $\%)$ & $\mathrm{HCO}_{3}{ }^{-}(\mathrm{mmol} / \mathrm{l})$ \\
\hline Control & $7.28 \pm 0.01$ & $6.1 \pm 0.5$ & $30.4 \pm 4.3$ & $99.4 \pm 0.2$ & $22.4 \pm 1.6$ \\
\hline Ischemic & $7.22 \pm 0.01^{*}$ & $7.6 \pm 0.3^{*}$ & $21.5 \pm 4.2$ & $96.4 \pm 0.8^{*}$ & $23.4 \pm 1.0$ \\
\hline
\end{tabular}

All data are expressed as mean \pm S.E.M. $(n=10)$ for control and ischemic group. * different from control group. Statistically significant differences were defined as $P<0.05$. sa $\mathrm{O}_{2}-\mathrm{O}_{2}$ saturation of arterial blood.

Table 2. Effect of transient BCCAO (PND 12) on duration of play and social behavior in prepubertal rats (PND 22) during 15 min session.

\begin{tabular}{|c|c|c|c|c|c|}
\hline \multirow[t]{2}{*}{ Group } & \multirow{2}{*}{$\begin{array}{c}\text { Social play } \\
\text { behavior } \\
\text { Pinning }\end{array}$} & \multicolumn{3}{|c|}{ Social behavior (unrelated to social play) } & \multirow{2}{*}{$\begin{array}{l}\text { Alone (distance in } \\
\text { pair } \geq 10 \mathrm{~cm} \text { ) }\end{array}$} \\
\hline & & $\begin{array}{l}\text { Mounting/ } \\
\text { crawling }\end{array}$ & Grooming & $\begin{array}{l}\text { Approaching/ } \\
\text { following }\end{array}$ & \\
\hline Control & $5.7 \pm 5.7$ & $64.6 \pm 10.6$ & $103.6 \pm 17.4$ & $354.6 \pm 20.1$ & $175.0 \pm 22.6$ \\
\hline Ischemic & $9.6 \pm 6.4$ & $81.0 \pm 10.9$ & $72.2 \pm 15.8$ & $351.8 \pm 14.5$ & $184.7 \pm 21.6$ \\
\hline
\end{tabular}

Data (in seconds) are expressed as mean \pm S.E.M. for couples/group ( $\mathrm{n}=9$ for control, $\mathrm{n}=11$ for post-ischemic group).

followed, $70 \mathrm{~ms}$ later, by the startle stimulus. For the evaluation of results we used values obtained from the 11 th -50 th trials of each tested animal, which consisted of 8 trials for each of the different PPs and the PA. The first block of trials (1st - 10th) was considered to be adaptation. Basal startle amplitude for each type of trial was calculated as the mean amplitude of the 8 trials and the percentage of PPI for each prepulse intensity (PP3, PP5 and PP10) was calculated as [100\% - (100\% x startle amplitude at PP)/PA]. Total PP (PPx) was given as the mean from all the different prepulses.

\section{Statistical analysis}

All the data were analysed using t-test statistics, except for the non-normally distributed pinning data where the Mann-Whitney test was used. All data are given as mean \pm S.E.M. Statistical analyses were performed using BMDP statistical software. $\mathrm{P}<0.05$ values were considered to be significant.

\section{Results}

Changes in arterial blood gases

A total of 10 rat pups from the sham-operated group and 10 pups from the experimental group were sampled $60 \mathrm{~min}$ after the surgical procedure. The blood samples in the experimental group showed a significant decrease in arterial $\mathrm{pH}(\mathrm{P}=0.001)$ and in the average $\mathrm{O}_{2}$ saturation of hemoglobin $\left(\mathrm{saO}_{2}\right) \quad(\mathrm{P}=0.002)$, but $\mathrm{pO}_{2}$ decline did not reach statistical significance (Table 1). With regard to $\mathrm{pCO}_{2}$, there was a significant increase $(\mathrm{P}=0.021)$, which however, was not accompanied by a significant increase in the concentration of $\mathrm{HCO}_{3}{ }^{-}$.

Social (play) behavior and social behavior unrelated to social play behavior on PND 22

Results from the social (play) recognition test are shown in Table 2. During 15 min sessions, pinning behavior in pairs of identically lesioned rats did not show any differences when compared to sham-operated littermates in total duration, frequency and latency to pinning behavior. This activity (pinning) was very poorly performed by all the tested animals (11-36\%), including other naive pairs (unpublished results) and, therefore, it could not be used as a meaningful evaluation of the change in this type of behavior. No significant differences in frequency, duration and latency were observed between sham-operated and post-ischemic animals in the other monitored behavioral parameters.

Open field test in pubertal rats on PND 35

Enhanced locomotor activity during the $5 \mathrm{~min}$ 
Table 3. Effect of transient BCCAO (PND 12) on frequency of locomotor activity (crossing and rearing), frequency of fine exploration (air and floor sniffing) and latency of immobilization (in seconds) during 5-min open field test in pubertal male rats (PND 35).

\begin{tabular}{cccccc}
\hline \multicolumn{1}{c}{ Group } & Crossing & Rearing & Immobility & Air sniffing & Floor sniffing \\
\hline Control $(n=10)$ & $54.0 \pm 6.5$ & $13.8 \pm 2.1$ & $200.0 \pm 29.2$ & $21.2 \pm 2.2$ & $58.8 \pm 5.4$ \\
Ischemic $(n=16)$ & $74.7 \pm 6.3^{*}$ & $20.0 \pm 2.1$ & $275.1 \pm 14.6^{*}$ & $17.1 \pm 2.1$ & $77.2 \pm 4.1^{*}$ \\
\hline
\end{tabular}

Data are expressed as mean \pm S.E.M. * significantly different $(P<0.05)$ from control group; $\mathrm{n}=$ number of animals.

Table 4. Effect of transient BCCAO (PND 12) on duration (in seconds) of immobility, air and floor sniffing during 5-min open field test in pubertal male rats (PND 35).

\begin{tabular}{lccc}
\hline Group & Immobility & $\begin{array}{c}\text { Air } \\
\text { sniffing }\end{array}$ & $\begin{array}{c}\text { Floor } \\
\text { sniffing }\end{array}$ \\
\hline $\begin{array}{l}\text { Control } \\
(n=10)\end{array}$ & $27.8 \pm 10.4$ & $67.4 \pm 10.8$ & $136.3 \pm 8.1$ \\
$\begin{array}{l}\text { Ischemic } \\
(n=16)\end{array}$ & $3.1 \pm 1.7^{*}$ & $37.8 \pm 5.7^{*}$ & $162.3 \pm 9.9$ \\
\hline
\end{tabular}

Data are expressed as mean \pm S.E.M. $*$ = different from control group. $P<0.05 ; \mathrm{n}=$ number of animals.

open field test (which measured ambulation, rearing counts, and the duration of immobility) was documented in pubertal post-ischemic rats (Table 3 and 4) compared to sham-operated rats. All data (which were analyzed using the Student t-test) showed significant differences between groups: "number of crossings" $(\mathrm{P}=0.039)$, "duration of immobility" $(\mathrm{P}=0.026)$ and "latency" of this parameter $(\mathrm{P}=0.017)$. However, the results for "frequency of rearing" ( $\mathrm{P}=0.060)$ were not significant. No difference was found in grooming between the experimental and the sham-operated group (data are not shown). Fine exploration activities were defined as air and floor sniffing (Tables 3 and 4). Variability of these behavioral activities was evaluated with $\mathrm{T}$-statistics and showed no difference in the frequency of air sniffing $(\mathrm{P}=0.214)$ between the groups. The slight decline in air sniffing between post-ischemic and sham-operated rats was statistically significant with regard to the duration of this behavioral activity $(\mathrm{P}=0.011)$. The significantly higher frequency of crossing activity seen in the post-ischemic rats was accompanied by a higher frequency of floor sniffing, but duration of floor sniffing was not significantly prolonged. In other behavioral activities no significant differences were found, including latency of defecation (used as a marker of emotionality).

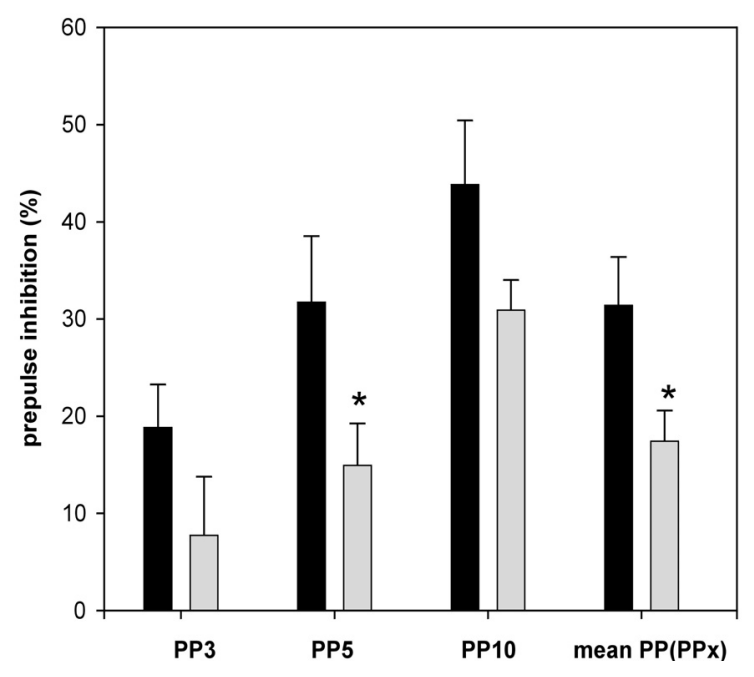

Fig. 1. Effect of bilateral common carotid artery occlusion (PND 12) on prepulse inhibition of the acoustic startle response (startle pulse $120 \mathrm{~dB}$ ) for prepulse (PPI) 3,5, $10 \mathrm{~dB}$ and average of all PPI (PPx) above background noise (grey bars, $n=11$ ) in comparison to sham-operated group (black bars, $\mathrm{n}=7$ ). Data are expressed as mean (in \%) inhibition of the startle response \pm S.E.M., * significantly different $(\mathrm{P}<0.05)$ from sham-operated group.

Open field test in young adult (post-pubertal) rats on PND 50

During the 5-min open field test no significant differences were found in any of the other investigated behavioral parameters including grooming (data not shown). There were no significant differences for crossing $(\mathrm{P}=0.101)$, rearing $(\mathrm{P}=0.098)$ or duration of immobility $(\mathrm{P}=0.806)$ including latency of this parameter $(\mathrm{P}=0.097)$.

\section{Acoustic startle response and its prepulse inhibition}

Male rats from the experimental group did not exhibit any significant differences in the response to a single acoustic startle reaction $(\mathrm{P} 120 \mathrm{~dB})$, when compared to the sham-operated (control) post-pubertal males on PND 50 (control: 104.3 \pm 34.2 , ischemic: $133.9 \pm$ 28.2, $\mathrm{P}=0.517$ ). An impairment of PPI observed after the neonatal ischemic episode was documented by a decrease 
in prepulse inhibition at PP5 and mean PP (PPx, calculated as the mean of PP3, PP5, PP10) in post pubertal rats (Fig. 1). For PP3 $(\mathrm{P}=0.206)$ and $\mathrm{PP} 10$ $(\mathrm{P}=0.065)$, the difference was not statistically significant, whereas the effect of BCCAO was seen in both PP5 $(\mathrm{P}=0.043)$ and $\mathrm{PPx}(\mathrm{P}=0.025)$.

\section{Discussion}

Short duration bilateral occlusion of the common carotid arteries (BCCAO) has been shown to induce a number of abnormalities in the brain and behavior of rats that are very similar to those seen in patients with schizophrenia. Therefore, long-lasting behavioral alterations following a hypoxic/ischemic episode may represent a useful endpoint for studying the efficacy of potential pharmacological treatments that may improve the behavioral consequences of obstetric complications involving brain ischemia in humans (Balduini et al. 2000). However, the behavioral effects of BCCAO have not been studied in detail (Boksa 2004). Our model used postnatal rats to approximate more closely the level of maturity seen in the human brain at birth.

Social play behavior, used as the earliest form of non-mother-directed social behavior (Vanderschuren et al. 1997), increases after PND 15 to a peak on PND 3036 and then gradually declines (Thor and Holloway 1984). This first social non-mother-directed behavior was not displayed in our experimental conditions to the extent described by other researchers. This behavioral feature cannot be explained by light conditions that could have depressed social play (Panksepp et al. 1984, Vanderschuren et al. 1995), because the lighting conditions were the same as those used in the animal housing room. We hypothesize that the reduced motivation to social play could be a result of too short period of maternal separation (only $3.5 \mathrm{~h}$ ) before testing with respect to weaning time (PND 28) which is the preferred weaning time in our animal house (Št'astný et al. 2004, 2005). On PND 28, rat adolescents have already established a typical daily rhythm (Nováková 1966, Girard et al.1991) and have completed changes in lipogenesis. Social behavior, unrelated to social play behavior, exhibited in the post-ischemic male rats showed no significant changes in contact behavior. These results suggest that the acute ischemic insult induced on PND 12 had only limited effects on social interaction behavior. We concluded that different breeding circumstances might play an important role in the performance of socialization processes evaluated by social (play) test, including the role of the mother as a mediator in the future behavior of pups.

One hour lasting bilateral occlusion of the common carotid arteries in 12-day-old rat pups induced enhanced locomotor activity (crossing) and depressed immobility in the open field paradigm in pubertal animals (on PND 35). Previous findings have shown both hyperactivity and hypoactivity as a consequence of neonatal hypoxia/ischemia (Speiser et al. 1983, Antier et al. 1998, Balduini et al. 2000, Ikeda et al. 2004, Lubics et al. 2005). With regard to locomotor activity, the protocol with the greatest similarity to ours, relative to the time of the ischemic insult was described by Decker et al. (2003), when very short intermittent burst of hypoxia over PND 7-11 resulted in hyperlocomotion of adult rats. Our observations showed that the differences in spontaneous activity, expressed as "crossing" during a 5 min session, between sham-operated and post-ischemic males decreased with age; in early adulthood the rats exhibited an almost normal pattern of exploration in the open field paradigm. This finding supports the idea of a compensatory mechanism that can mitigate the effects of the perinatal insults, and which expressed itself as a higher level of plasticity in the neonatal rat brain (Balduini et al. 2000).

However, in our model the effects of one hour of continuous bilateral common carotid artery occlusion in 12-day-old rat pups were still present in early adulthood (PND 50) as a deficit in prepulse inhibition (without altered basal startle amplitude) in post-ischemic animals. Strong evidence indicates that PPI is regulated by the nucleus accumbens, more specifically, by its dopaminergic inputs, and disruption of PPI by DA agonists (i.e. apomorphine) are frequently used as an animal model of PPI deficits in schizophrenic subjects (Geyer et al. 2001). Jansen and Low (1996) showed that using neonatal ischemic-hypoxic brain injury based on the protocol of Rice et al. (1981) produced sensorimotor deficits in adult animals. However, this deficit was examined, not by using the prepulse inhibition paradigm, but by measuring the time during which the animals were able to remain on a rotating treadmill. Our findings documented the possible role of ischemic lesions, induced relatively late in the development of rat brains, on information-processing and modulation of PPI and potential deficits in brain structures associated with neuronal circuits involved in sensorimotor gating. 
In summary, we have shown that one hour of continuous hypoperfusion of neonatal rat brains can induce behavioral deficits in young adult males that are relevant to schizophrenia. When 12-day-old male rats were subjected to transient brain ischemia and then tested as adolescent and young adult rats, they displayed a change in their reaction to novelty and to prepulse inhibition of the acoustic startle. The present study supports the model of schizophrenia as a neurodevelopmental disorder. We believe that early cerebral hypoperfusion is a factor in later neurodevelopment and consequently has the potential to alter CNS function.
These alterations can be linked with the manifestations of neuropsychiatric disorders. Thus, even though genetic vulnerability plays a major role in the development of schizophrenia, these findings suggest that obstetric complications also contribute as epigenetic factors in the etiology of schizophrenia.

\section{Acknowledgements}

This work was supported by grants MH0PCP2005 and NR8797-4/2006 from MHCR. Mrs. Budínová and Mrs. Horníková are gratefully acknowledged for skilful technical assistance.

\section{References}

ANTIER D, ZHANG B-L, MAILLIET F, AKOKA S, POURCELOT L, SANNAJUST F: Effects of neonatal focal cerebral hypoxia-ischemia on sleep-waking pattern, ECoG power spectra and locomotor activity in the adult rat. Brain Res 807: 29-37, 1998.

BAYER SA, ALTMAN J, RUSSO R, ZHANG Y: Timetables of neurogenesis in the human brain based on experimentally determined patterns in the rat. Neurotoxicology 14: 83-144, 1993.

BALDUINI W, DE ANGELIS V, MAZZONI E, CIMINO M: Long-lasting behavioral alterations following a hypoxic/ischemic brain injury in neonatal rats. Brain Res 859: 318-325, 2000.

BENEŠOVÁ O, TEJKALOVÁ H, KRIŠTOFIKOVÁ Z, HUŠEK P, NEDVÍDKOVÁ J, YAMAMOTOVÁ A: Brain maldevelopment and neurobehavioural deviations in adult rats treated neonatally with indomethacin. Eur Neuropsychopharmacol 11: 367-373, 2001.

BOKSA P: Animal models of obstetric complications in relation to schizophrenia. Brain Res Rev 45: 1-17, 2004.

BUBENÍKOVÁ-VALEŠOVÁ V, BALCAR VJ, TEJKALOVÁ H, LANGMEIER M, ŠŤASTNÝ F: Neonatal administration of $\mathrm{N}$-acetyl-L-aspartyl-L-glutamate induces early neurodegeneration in hippocampus and alters behaviour in young adult rats. Neurochem Int 48: 515-522, 2006.

CANNON TD, ROSSO IM, HOLLISTER JM, BEARDEN CE, SANCHEZ LE, HADLEY TA: A prospective cohort study of genetic and perinatal influences in the etiology of schizophrenia. Schizophr Bull 26: 351-366, 2000.

CANNON M, JONES PB, MURRAY RM: Obstetric complications and schizophrenia: historical and meta-analytic review. Am J Psychiatry 159: 1080-1092, 2002.

CANNON M, DEAN K, JONES PB: Early environmental risk factors for schizophrenia. In: Neurodevelopment and Schizophrenia. KESHAVAN MS, KENNEDY JL, MURRAY RM (eds), Cambridge University Press, 2004, pp 191-209.

CHOY M, GANESAN CM, THOMAS DL, THORNTON JS, PROCTOR E, KING MD, VAN DER WEERD L, GADIAN DG, LYTHGOE MF: The chronic vascular and haemodynamic response after permanent bilateral common carotid occlusion in newborn and adult rats. J Cereb Blood Flow Metab 26: 1066-1075, 2006.

DALMAN C, THOMAS HV, DAVID AS, GENTZ J, LEWIS P, ALLEBECK P: Signs of asphyxia at birth and the risk of schizophrenia. Population-based case-control study. Br J Psychiatry 179: 403-408, 2001.

DECKER MJ, HUE GE, CAUDLE WM, MILLER GW, KEATING GL, RYE DB: Episodic neonatal hypoxia evokes executive dysfunction and regionally specific alterations in markers of dopamine signalling. Neuroscience 117 : 417-425, 2003.

DONÁT P: Measuring behaviour: the tools and the strategies. Neurosci Biobehav Rev 15: 447-454, 1991.

ELLENBROEK BA, COOLS AR: Early maternal deprivation and prepulse inhibition: the role of the postdeprivation environment. Pharmacol Biochem Behav 73: 177-184, 2002. 
GEYER MA, KREBS-THOMSON K, BRAFF DL, SWERDLOW NR: Pharmacological studies of prepulse inhibition model of sensorimotor gating deficits in schizophrenia: a decade in review. Psychopharmacology 70: 699-707, 2001.

GIRARD J, PERDEREAU D, NARKEWICZ M, COUPÉ C, FERRÉ P, DECAUX JF, BOSARD P: Hormonal regulation of liver phosphoenolpyruvate carboxykinase and glucokinase gene expression at weaning in the rat. Biochimie 73: 71-76, 1991.

HARRISON PJ: The neuropathology of schizophrenia. A critical review of the data and their interpretation. Brain 122: 593-624, 1999.

IKEDA T, MISHIMA K, AOO N, EGASHIRA N, IWASAKI K, FUJIWARA M, IKENOUE T: Combination treatment of neonatal rats with hypoxia-ischemia and endotoxin induced long-lasting memory and learning impairment that is associated with extended cerebral damage. Am J Obst Gyn 191: 2132-2141, 2004.

JANSEN EM, LOW WC: Long-term effect of neonatal ischemic-hypoxic brain injury on sensorimotor tasks in rats. Behav Brain Res 78: 189-194, 1996.

JÍLEK L, ANTOŠOVÁ E, DRAVID AR, FISCHER J, HABER B, JANATA V, KRÁLOVÁ A, KRÁSNÝ J, KRULICH L, RYCHLÍK I, SIRAKOVA I, SIRAKOV L, TRÁVNÍČKOVÁ E, TROJAN S, VEČEREK B, WAGNER J: The metabolic adaptive reaction of the immature nervous tissue to stagnant hypoxia. In: Ontogenesis of the Brain, Vol. 1. L. JÍLEK, S. TROJAN (eds), Charles University Press, Prague, 1968, pp. 143-157.

JONES PB, RANTAKALLIO P, HARTIKAINEN AL, ISOHANNI M, SIPILA P: Schizophrenia as a long-term outcome of pregnancy, delivery, and perinatal complications: a 28-year follow-up of the 1966 North Finland general population birth cohort. Am J Psychiatry 155: 355-364, 1998.

JONES RD, MORICE AH, EMERY JC: Effects of perinatal exposure to hypoxia upon the pulmonary circulation of the adult rat. Physiol Res 53: 11-17, 2004.

LUBICS A, REGLÖDI D, TAMAS A, KISS P, SZALAI M, SZALONTAY L, LENGVÁRI I: Neurological reflexes and early motor behavior in rats subjected to neonatal hypoxic-ischemic injury. Behav Brain Res 157: 157-165, 2005.

MARENCO S, WEINBERGER DR: The neurodevelopmental hypothesis of schizophrenia: following a trail of evidence from cradle to grave. Dev Psychopathol 12: 501-527, 2000.

MURRAY RM, LEWIS SW: Is schizophrenia a neurodevelopmental disorder? Br Med J 29: 681-682, 1987.

NOVÁKOVÁ V: Weaning of young rats. Effect of time on behavior. Science 151: 475-476, 1966.

PANKSEPP J, SIVIY SM, NORMANSELL L: The psychobiology of play. Theoretical and methodological perspectives. Neurosci Biobehav Rev 8: 465-492, 1984.

RANTAKALLIO P, VON WENDT L, KOIVU M: Prognosis of perinatal brain damage: a prospective study of a one year birth cohort of 12000 children. Early Hum Dev 15: 75-84, 1987.

RICE JE, VANNUCCI RC, BRIERLEY JB: The influence of immaturity on hypoxic-ischemic brain damage in the rat. Ann Neurol 9: 131-141, 1981.

ROMIJN HJ, HOFMAN MA, GRAMSBERGEN, A: At what age is the developing cerebral cortex of the rat comparable to the full-term human newborn baby? Early Hum Dev 26: 61-68, 1991.

SANDAGER-NIELSEN K, ANDERSEN MB, SAGER TN, WERGE T, SCHEEL-KRÜGER J: Effects of postnatal anoxia on striatal dopamine metabolism and prepulse inhibition in rats. Pharmacol Biochem Behav 77: 767$774,2004$.

SPEISER Z, KORCZYN AD, TEPLITZKY I, GITTER S: Hyperactivity in rats following postnatal anoxia. Behav Brain Res 7: 379-382, 1983.

ŠŤASTNÝ F, ANTOŠOVÁ E, KOŠTÍŘ J, JÍLEK L: Effect of stagnant hypoxia on ATP, $\mathrm{Na}^{+}-\mathrm{K}^{+}-\mathrm{ATPase}$, and electrolyte content in the developing rat brain. Brain Res 33: 597-600, 1971.

ŠŤASTNÝ F, TEJKALOVÁ H, SKUBA I, PÁLENÍČEK T, PLISS L, MAREŠ V, BUBENÍKOVÁ V, BALCAR VJ: Interactions of dopamine D1/D2 receptor with glutamate receptor of NMDA type: from molecules to animal models of schizophrenia. Psychiatrie 8 (Suppl 3): 30-39, 2004. 
ŠŤASTNÝ F, TEJKALOVÁ H, SKUBA I, BALCAR VJ, KAISER M, YONEDA Y: Quinolinic acid, $N$-methyl-Daspartate receptor and schizophrenia: Testing and integrative theory. In: Amino Acid Signalling 04, YUKIO Y (ed), Research Sign Post, Trivandrum, Kerala, India, 2005, pp 67-83.

THOR DH, HOLLOWAY WR: Developmental analyses of social play behaviour in juvenile rats. Bull Psychosom Soc 22: 587-90, 1984.

TROJAN S, ŠŤASTNÝ F: Hypoxia and the developing brain. In: Handbook of Human Growth and Developmental Biology Volume I, Part C, MEISAMI E, TIMIRAS PS (eds), CRC Press Inc, Boca Raton, Florida. 1988, pp 101-123.

UEHARA H, YOSHIOKA H, KAWASE S, NAGAI H, OHMAE T, HASEGAWA K, SAWADA T: A new model of white matter injury in neonatal rats with bilateral carotid artery occlusion. Brain Res 837: 213-220, 1999.

VERDOUX H, MURRAY RM: Prenatal and perinatal risk factors for schizophrenia: data and doubts. Nerosci News 1: 18-21, 1998.

VANDERSCHUREN LJ, NIESINK RJ, VAN REE JM: Influence of environmental factors on social play behaviour of juvenile rats. Physiol Behav 58: 119-123, 1995.

VANDERSCHUREN LJ, NIESINK RJ, VAN REE JM: The neurobiology of social play behaviour in rats. Neurosci Biobehav Rev 21: 309-326, 1997.

WEINBERGER DR: Implications of normal brain development for the pathogenesis of schizophrenia. Arch Gen Psychiatry 44: 660-667, 1987.

ZORNBERG GL, BUKA SL, TSUANG MT: Hypoxic-ischemia-related fetal/neonatal complications and risk of schizophrenia and other nonaffective psychoses: a 19-year longitudinal study. Am J Psychiatry 157: 196-202, 2000 .

\section{Corresponding author}

H. Tejkalová, Laboratory of Biochemistry and Brain Pathophysiology, Prague Psychiatric Center, Ústavní 91, 18103 Prague 8, Czech Republic. Fax: +420-266003160. E-mail: tejkalova@pcp.lf3.cuni.cz 